\title{
DAMPAK PURSED LIPS BREATHINGEXERCISE TERHADAP PENURUNAN KELUHAN SESAK NAPAS PADA PASIEN PPOK
}

\author{
THE IMPACT OF PURSED LIPS BREATHING EXERCISE ON DECREASING \\ COMPLAINTS OF SHORTNESS OF BREATH IN COPD PATIENTS
}

\author{
Lestari Lorna Lolo ${ }^{1}$, Grace Tedy Tulak ${ }^{2}$ \\ ${ }^{1,2,}$ STIKes Kurnia Jaya Persada, \\ Alamat Korespondensi : thenextambition1@gmail.com
}

\section{ABSTRACT}

Background: shortness of breath experienced by people with COPD quite disturbing daily activities, so that the quality of life of patients will decrease. Therefore, COPD sufferers need treatment that can reduce shortness of breath and improve the respiratory quality of COPD patients. PLB is the focus of researchers because it is able to help overcome complaints of shortness of breath is also easy to do by sufferers independently and does not require costs in its implementation so that the family economy is not disrupted.

Objective: to determine the impact of Pursed Lips Breathing Exercise on decreasing complaints of shortness of breath in COPD patients.

Method: the experimental design method used in this study used the PreExperimental Design with the One group pre and posttest design method.

Results: The study found that based on the Wilcoxon Signed Ranks Test analysis and obtained a $p$ value of 0,000 smaller than the value of $\alpha=0.05$ which means that $\mathrm{Ha}$ is accepted and $\mathrm{HO}$ is rejected.

Conclusion: there are differences in complaints of shortness of breath of COPD patients after $P B L$ interventions, namely decreased complaints of shortness of breath of patients.

Keywords - COPD, PBL, shortness of breath

\begin{abstract}
ABSTRAK
Latar Belakang : sesak napas yang dialami oleh penderita PPOK cukup mengganggu aktifitas sehari-hari, sehingga kualitas hidup penderita akan menurun. Oleh karena itu, penderita PPOK membutuhkan penanganan yang dapat menurunkan sesak napas dan meningkatkan kualitas pernapasan pasien PPOK. PLB menjadi focus peneliti karena mampu membantu mengatasi keluhan sesak napas juga mudah untuk dilakukan oleh penderita secara mandiri dan tidak membutuhkan biaya dalam pelaksanaannya sehingga ekonomi keluarga tidak terganggu.
\end{abstract}

Tujuan : untuk mengetahui dampak Pursed Lips BreathingExercise terhadap penurunan keluhan sesak napas pada pasien PPOK.

Metode : rancangan metode eksperimen yang digunakan dalam penelitian ini menggunakan Pre-Eksperimental Design dengan metode One group pre and posttest design.

Hasil : penelitian menemukan bahwa berdasarkan uji analisa Wilcoxon Signed Ranks Test dan diperoleh nilai $\mathrm{p}$ value 0,000 lebih kecil dari nilai $\alpha=0,05$ yang artinya $\mathrm{Ha}$ diterima dan $\mathrm{HO}$ ditolak.

Simpulan : terdapat perbedaan keluhan sesak napas pasien PPOK setelah dilakukan intervensi PBL yaitu menurunnya keluhan sesak napas pasien.

Kata kunci-PPOK, PBL, sesak napas 


\section{PENDAHULUAN}

Tanda dan gejala dari PPOK antara lain penurunan fungsi aliran udara dan adanya napas pendek, atau dispnea, adanya batuk, wheezing, produksi sputum (mucus atau dahak) dan nilai Indeks Brinkman $\leq$ 200. (BMJ dan COPD, 2017)

\section{Pursed Lips Breathing (PBL)} adalah salah satu breathing exercise yang tepat diterapkan pada pasien PPOK karena mudah dan mampu meningkatkan kemampuan pernapasan (GOLD, 2017).

\section{World Health Organitation (WHO)} memprediksi bahwa pada tahun 2030 PPOK akan menjadi salah satu penyakit penyebab kematian tertinggi ke tiga di dunia (WHO, 2017). Hasil Riskesdas tahun 2013 yang dilakukan di 33 propinsi, 497 Kabupaten/Kota, dan 294.959 rumah tangga bahwa 56,7\% laki-laki di Indonesia adalah perokok (Riskesdas, 2013). Data dari dinas Kesehatan Kota Palopo terdapat sebanyak 56 pasien PPOK pada bulan januari-mei 2017.

PPOK adalah penyakit kronis saluran napas yang ditandai dengan hambatan aliran udara khususnya udara ekspirasi dan bersifat progresif lambat (semakin lama semakin memburuk), disebabkan oleh pajanan faktor risiko seperti merokok, polusi udara di dalam maupun di luar ruangan. Seseorang dikatakan menderita PPOK jika pernah mengalami sesak napas yang bertambah ketika beraktifitas dan/atau bertambah dengan meningkatnya usia disertai batuk berdahak atau pernah mengalami sesak napas disertai batuk berdahak. Sesak napas yang dialami oleh penderita PPOK cukup mengganggu aktifitas sehari-hari, sehingga kualitas hidup penderita akan menurun. Oleh karena itu, penderita PPOK membutuhkan penanganan yang dapat menurunkan sesak napas dan meningkatkan kualitas pernapasan pasien PPOK. PLB menjadi focus peneliti karena mampu membantu mengatasi keluhan sesak napas juga mudah untuk dilakukan oleh penderita secara mandiri dan tidak membutuhkan biaya dalam pelaksanaannya sehingga ekonomi keluarga tidak terganggu. 
Penelitian ini bertujuan untuk mengetahui dampak Pursed Lips Breathing Exercise terhadap penurunan keluhan sesak napas pada pasien PPOK.

\section{METODE PENELITIAN}

Rancangan metode eksperimen yang digunakan dalam penelitian ini menggunakan Pre-Eksperimental Design dengan metode One group pre and posttest design. Penelitian ini menggunakan data primer dan sekunder yang akan diolah dengan uji $\mathrm{T}$ Test dengan tingkat kemaknaan $\leq 0,05$. Penelitian ini menggunakan etika penelitian dalam pelaksanaannya yaitu prinsip SelfDetermination, Anonymity atau Confidentiality, Benefience dan Justice.

Sebelum intervensi PBL ini dilaksanakan, terlebih dahulu akan dilakukan pendidikan kesehatan tentang PBL dan PPOK pada pasien dan keluarga dengan tujuan agar keluarga dan pasien memiliki pengetahuan tentang pelaksanaan PBL yang baik dan benar sehingga saat pelaksanaan intervensi penelitian pasien dapat melaksanakan PBL dengan tepat, selain itu, keluarga yang dilibatkan dalam pendidikan kesehatan akan dibentuk menjadi tim pengawas sekaligus pendukung utama pelaksanaan PBL pada pasien PPOK. Penelitian ini dilaksanakan di Kota Palopo.

\section{HASIL dan PEMBAHASAN}

Karakteristik Responden

Tabel 1

Distribusi Frekuensi Karakteristik Responden

\begin{tabular}{lcc}
\hline \multicolumn{1}{c}{ Karakteristik } & n & $(\%)$ \\
\hline Usia & & \\
$<18$ tahun & 2 & 3.6 \\
18-59 tahun & 41 & 73.2 \\
$\geq 60$ tahun & 13 & 23.2 \\
Jenis kelamin & & \\
Laki-laki & 33 & 58.9 \\
Perempuan & 23 & 41.1 \\
Pendidikan & & \\
Rendah & 30 & 53.6 \\
Tinggi & 26 & 46.4 \\
Status Ekonomi & & \\
Rendah & 11 & 19.6 \\
Cukup & 45 & 80.4 \\
Status merokok & & \\
Merokok & 31 & 55.4 \\
$\quad$ Tidak merokok & 25 & 44.6 \\
Total & 56 & 100.0 \\
\hline Sumber : data primer 2019 & &
\end{tabular}

Berdasarkan data tabel 1diatas diperoleh bahwa dari 56 responden terdapat responden dengan usia $<18$ tahun sebanyak 2 orang $(3,6 \%)$, usia 18-59 tahun sebanyak 41 orang $(73,2 \%)$ dan $\geq 60$ tahun sebanyak 13 orang $(23,2 \%)$, berdasarkan jenis kelamin terdapat jenis kelamin lakilaki sebanyak 33 orang $(58,9 \%)$ dan jenis kelamin perempuan sebanyak 23 orang 
$(41,1 \%)$. Berdasarkan tingkat pendidikan terdapat pendidikan rendah sebanyak 30 orang $(53,6 \%)$ dan pendidikan tinggi sebanyak 26 orang $(46,4 \%)$. Berdasarkan status ekomoni terdapat status ekonomi rendah sebanyak 11 orang $(19,6 \%)$ dan ekonomi cukup sebanyak 45 orang $(80,4 \%)$. Berdasarkan status merokok terdapat status merokok sebanyak 31 orang $(55,4 \%)$ dan tidak merokok sebanyak 25 orang $(44,6 \%)$.

\section{Analisis univariat}

Tabel 2

Distribusi Responden berdasarkan keluhan sesak sebelum dan sesudah intervensi PBL

\begin{tabular}{|c|c|c|c|c|}
\hline \multirow[b]{2}{*}{$\begin{array}{c}\text { Keluhan } \\
\text { sesak }\end{array}$} & \multicolumn{2}{|c|}{$\begin{array}{l}\text { Sebelum } \\
\text { PBL }\end{array}$} & \multicolumn{2}{|c|}{ Setelah PBL } \\
\hline & $\begin{array}{l}\text { Frek } \\
\text { uensi }\end{array}$ & $\begin{array}{c}\text { Persen } \\
(\%)\end{array}$ & $\begin{array}{c}\text { Fre } \\
\text { kue } \\
\text { nsi }\end{array}$ & $\begin{array}{c}\text { Persen } \\
(\%)\end{array}$ \\
\hline Sesak & 55 & 98,2 & 3 & 5,4 \\
\hline $\begin{array}{l}\text { Tidak } \\
\text { sesak }\end{array}$ & 1 & 1,8 & 53 & 94,6 \\
\hline Total & 56 & 100.0 & 56 & 100.0 \\
\hline
\end{tabular}

Berdasarkan data tabel 2 diperoleh bahwa jumlah keluhan sesak sebelum intervensi PBL dilakukan yang mengeluh sesak sebanyak 55 orang $(98,2 \%)$ dan tidak sesak sebanyak 1 orang $(1,8 \%)$. Data jumlah keluhan sesak setelah intervensi sebanyak 3 orang $(5,4 \%)$ dan tidak sesak sebanyak 53 orang $(94,6 \%)$.

\section{Analisis Bivariat}

Tabel 3

Deskripsi Statistik dampak PBL terhadap keluhan sesak pasien PPOK

\begin{tabular}{lcccc}
\hline & $\begin{array}{c}\text { Minim Maxi } \\
\text { um }\end{array}$ & mum & Mean & $\begin{array}{c}\text { Std. } \\
\text { Deviation }\end{array}$ \\
\hline $\begin{array}{l}\text { Dampak PBL } \\
\text { terhadap }\end{array}$ & 20 & 28 & 25.0000 & 1.58401 \\
$\begin{array}{l}\text { keluhan sesak } \\
\text { sebelum PBL }\end{array}$ & & & & \\
$\begin{array}{l}\text { Dampak PBL } \\
\text { terhadap } \\
\text { keluhan sesak } \\
\text { sebelum PBL }\end{array}$ & 16 & 24 & 16.5357 & 1.683777 \\
\hline $\begin{array}{l}\text { Sumber : data primer 2019 } \\
\text { Sumber }\end{array}$ & & & \\
\hline
\end{tabular}

Berdasarkan data tabel 3 diperoleh data nilai jumlah sesak minimum sebelum PBL adalah 20 dan setelah PBL adalah 16.Nilai maximum jumlah sesak sebelum PBLadalah 28 dan setelah PBL adalah 24.Nilai mean sebelum PBL adalah 25.0000 dan setelah PBL16.5357. Nilai Std. Deviation sebelum PBL adalah 1.58401 dan setelah edukasi 1.683777 .

Tabel 4

Uji Dampak PBL terhadap penurunan keluhan sesak pasien PPOK

Ranks

\begin{tabular}{|c|c|c|c|c|}
\hline & & $\mathrm{N}$ & $\begin{array}{l}\text { Mean } \\
\text { Rank }\end{array}$ & $\begin{array}{c}\text { Sum } \\
\text { of } \\
\text { Ranks }\end{array}$ \\
\hline \multirow{4}{*}{$\begin{array}{c}\text { Keluhan sesak } \\
\text { napas sebelum } \\
\text { PBL - keluhan } \\
\text { sesak napas } \\
\text { setelah PBL }\end{array}$} & $\begin{array}{l}\text { Negative } \\
\text { Ranks }\end{array}$ & $56^{\mathrm{a}}$ & 28.50 & 1596.0 \\
\hline & $\begin{array}{l}\text { Positive } \\
\text { Ranks }\end{array}$ & $0^{\mathrm{b}}$ & \multirow[t]{3}{*}{0.00} & \multirow[t]{3}{*}{0.00} \\
\hline & Ties & $0^{c}$ & & \\
\hline & Total & 56 & & \\
\hline
\end{tabular}

Tabel 5

Uji Statistik

\begin{tabular}{lc}
\hline & $\begin{array}{c}\text { Keluhan sesak sebeum PBL- } \\
\text { keluhan sesak setelah PBL }\end{array}$ \\
\hline $\mathrm{Z}$ & $-6.574^{\mathrm{b}}$ \\
$\begin{array}{l}\text { Asymp. Sig. (2- } \\
\text { tailed) }\end{array}$ & 0,000 \\
\hline
\end{tabular}


Berdasarkan uji analisa Wilcoxon

Signed Ranks Test dan diperoleh nilai $\mathrm{p}$ value 0,000 lebih kecil dari nilai $\alpha=0,05$ yang artinya Ha diterima dan $\mathrm{H} 0$ ditolak atau terdapat perbedaan keluhan sesak napas pasien PPOK setelah dilakukan intervensi PBL.

Hasil penelitian ini sejalan dnegan hasil penelitian yang dilakukan oleh Adhitya Kusuma Bakti (2015) dengan hasil analisa data tentang pengaruh Pursed Lip Breathing Exercise terhadap penurunan tingkat sesak napas menggunakan uji wilcoxon test yaitu kelompok kontrol $\mathrm{P}=0,014$, kelompok perlakuan $\mathrm{P}=0,002$

Hasil penelitian ini didukung pula hasil penelitain yang dilakukan oleh Baiq Widia (2017) menemukan bahwa ada pengaruh penambahan peningkatan kapasitas vital paru sebelum dan sesudah intervensi pada pursed lips breathing pada diaphragma breathing terhadap peningkatan kapasitas vital paru pada $\operatorname{PPOK}(\mathrm{p}=0,000)$.
Berdasarkan hasil penelitian diperoleh bahwa keluhan sesak napas pasien PPOK sebelum PBL yang mengeluh sesak napas sebanyak 55 orang responden $\quad(98,2 \%)$. Sesak napas merupakan suatu kondisi bernapas yang dirasakan tidak seperti biasa/seharusnya yang biasanya. (Douglas, 2014)

Keluhan sesak napas dalam penelitian ini merujuk pada teori yang disampaikan oleh Bickley (2012) yang menyatakan bahwa nilai normal pernapasan pasien dewasa adalah 14-20 kali per menit karena itu, dalam penelitian ini frekuensi nafas pasien dihitung mengalami sesak napas jika frekuensi napas > $20 \mathrm{kali} / \mathrm{menit}$ (Bicley, 2012)

Sesak napas yang dialami oleh pasien PPOK sering kali menjadi hambatan dalam melakukan aktivitas. Sesak napas yang dialami oleh pasien PPOK yang sudah berlangsung lama kan membuat pasien sudah beradaptasi dan merasa bahwa tidak lagi merasa sesak. Namun, seringkali saat beraktifitas pasien kembali mengeluh mengalami sesak 
napas.Keluhan sesak napas diungkapkan setiap kali berjalan kaki beberapa puluh meter, saat berjalan keluar masuk rumah, naik turun tangga atau berkunjung kerumah tetangga). Keluhan sesak paling banyak disampaikan oleh responden dengan rentang usia 50 tahun keatas.

Keluhan sesak napas responden setelah intervensi PBL yang mengeluh sesak napas sebanyak 3 orang $(5,4 \%)$. Adanya responden yang masih mengeluh sesak pada penelitian ini ditemukan pada responden dengan klasifikasi usia $\geq 60$ tahun, dimana semakin meningkat usia seseorang risiko mengalami penurunan kesehatan dan fisik semakin meningkat, seperti yang disampaikan oleh Oemiati (2013) bahwa faktor risiko lain peenyebab PPOK yaitu usia. Selain itu, responden tersebut juga memiliki riwayat merokok, pasien PPOK yang memiliki riwayat merokok walaupun telah berhenti namun riwayat merokok sebelumnya dapat memperparah kondisi.Seorang perokok yang aktif akan mengalami hipersekresi produksi mucus adan sumbatan jalan napas
(Oemiati, 2013). Pasien PPOK yang memiliki riwayat merokok biasanya telah merokok > 20 bungkus tahun. Douglas, Nicol, \& Robertson (2014) menjabarkan perhitungan bungkus tahun perokok sebagai berikut :

(jumlah rokok yang dihisap/hari x jumlah tahun merokok) Asap rokok yang dihisap oleh perokok dapat menyebabkan iritasi kronik pasien PPOK. Mekanisme iniyang rutin dibicarakan pada bronchitis kronis, sedangkan pada emfisema paru, ketidakseimbangan pada protease dananti protease serta defisiensi $\alpha$ 1antitripsin menjadi dasar pathogenesis PPOK. Proses inflamasi yang melibatkan netrofil, makrofag dan limfosit akan melepaskan mediator mediator inflamasi dan akan berinteraksi dengan struktursel pada saluran nafas dan parenkim. Secara umum, perubahan struktur daninflamasi saluran nafas ini meningkatseiring derajat keparahan penyakit dan menetap meskipun setelah berhenti merokok (Susanti, 2015).

Intervensi PBL yang dilakukan secara signifikan mampu menurunkan keluhan sesak napas pasien PPOK. 
Penerapan PBL dengan teratur, responden tidak lagi mengeluh mengalami sesak napas saat naik turun tangga, berjalan beberapa puluh meter (ke rumah tetangga), berjalan cepat atau keluar masuk rumah sambil berlari-lari.

\section{SIMPULAN}

Berdasarkan hasil penelitian diperoleh bahwa jumlah keluhan sesak sebelum intervensi PBL dilakukan yang mengeluh sesak sebanyak 55 orang $(98,2 \%)$ dan tidak sesak sebanyak 1 orang $(1,8 \%)$. Data jumlah keluhan sesak setelah intervensi sebanyak 3 orang $(5,4 \%)$ dan tidak sesak sebanyak 53 orang $(94,6 \%)$. Berdasarkan hasil uji analisa Wilcoxon Signed Ranks Test dan diperoleh nilai $\mathrm{p}$ value 0,000 lebih kecil dari nilai $\alpha=0,05$ yang artinya Ha diterima dan $\mathrm{H} 0$ ditolak atau terdapat perbedaan keluhan sesak napas pasien PPOK setelah dilakukan intervensi PBL.

\section{UCAPAN TERIMA KASIH / ACKNOWLEDGEMENT}

Terima kasih peneliti haturkan kepada :

1. Kementrian Riset Teknologi dan Pendidikan Tinggi yang telah memberikan bantuan dana hibah penelitian yang diberikan kepada peneliti

2. Lembaga Layanan Pendidikan Tinggi (LLDIKTI) wilayah IX Sulawesi dan Gorontalo atas kepercayaan yang telah diberikan pada peneliti.

3. Dinas Penanaman Modal dan Pelayanan Terpadu Satu Pintu Kota Palopo atas kemudahan akses pelayanan perijinan.

4. Dinas kesehatan Kota Palopo atas pelayanan dan kemudahan akses informasi dan data.

5. Ketua STIKes Kurnia Jaya Persada Palopo

\section{REFERENCES}

BMJ Publishing Group Limited. 2017. COPD. Diakses pada tanggal 21 Juni 2018 dari http://bestpractice. bmj.com.

COPD Foundation. 2017. Living with COPD breathing techniques. Diakses pada tanggal 29 mei 20187 dari https://www.copdfoundation.org. 
The Global Initiative for Chronic Obstructive Lung Disease (GOLD). 2017. GOLD 2017 Global Strategy for the Diagnosis, Management and Prevention of COPD. Diakses pada tanggal $21 \quad 2018 \quad$ dari http://goldcopd.org.

Philip Eng Respiratory \& Medical Clinic. 2017. COPD. Diakses pada tanggal 25 Juni dari .http://www.philipeng. com.sg

Ries AL, Bauldoff GS, Carlin BW, Casaburi R, Emery CF, Mahler DA, Make B, Rochester CL, Zuwallack R, Herrerias C. 2007. Pulmonary Rehabilitation: Joint ACCP/ AACVPR Evidence-Based Clinical Practice Guidelines. PMID: 17494825 DOI: 10.1378/chest.062418 Diakses pada tanggal 24 Juni dari https://www.ncbi.nlm.nih.gov/ pubmed/17494825.

Tan, W. e. (2013). Article: COPD Prevalence in 12 Asia-Pacific Countries and Regions: Projections Based on the COPD Prevalence Estimation Model. The HKU Scholars Hub Respirology Vol. 8, 192-198.

Anne Maree Kelly, A. H. (2018). Epidemiology, treatment, disposition and outcome of patients with acute exacerbation of COPD presenting to emergency departments in Australia and South East Asia: An
AANZDEM study. Respirology Volume23, Issue7, pages 681-686, https://doi.org/10.1111/resp.13259, diakses pada tanggal 21 juni 2018 dari https://onlinelibrary.wiley.com/ doi/abs/10.1111/resp.13259.

BIBLIOGRAPHY VI 1033 Noppawan

Charususin, S. D. (2018). Respiratory muscle function and exercise limitation in patients with chronic obstructive pulmonary disease: a review. Expert Review of Respiratory Medicine, Vol 12, issue 1, 67-79, DOI: 10.1080/17476348. 2018.1398084, diakses pada tanggal 21 juni 2018 dari https://www.tandf online.com/doi/abs/10.1080/1747634 8.2018.1398084.

Baiq Widia, S. K. (2017). pengaruh penambahan pursed lips breathing pada diaphragma breathing terhadap. Retrieved Juni 21, 2018, from digilib.unisayogya.ac.id: http://digilib.unisayogya.ac.id/2784/ 1/NASKAH\%20PUBLIKASI\%200 K.pdf.

Dika Rizki Imania, K. T. (2015). Breathing exercise sama baiknya dalam meningkatkan kapasitas vital (kv) dan volume ekspirasi paksa detik pertama (vep1) pada tenaga sortasi yang mengalami gangguan paru di pabrik teh pt. Candi loka jamus ngawi. Sport and Fitness Journal, Volume 3, No.3 : 38-46, Nopember 
2015, ISSN : 2302-688X, di akses pada tanggal 21 Juni 2018 dari https://ojs.unud.ac.id/index.php/spor/ article/view/16630/10911.

Erma Yulianti, N. K. (2017). Pengaruh Pursed Lips Breathing Exercise Terhadap Perubahan Derajat Sesak Napas pada Pasien Penyakit. Retrieved Juni 21, 2018, from Library Universitas Muhammadiyah Banjarmasin: http://idr-library.um bjm.ac.id/66/10/MANUSKRIP.pdf

Clevelandclinic. 2017. Pursed Lips breathing. Diakses pada tangga 29 mei 2017 dari HYPERLINK "https://my.clevelandclinic.org" https://my.clevelandclinic.org

Foundation, C. (2018). Breathing Exercises and Techniques. Retrieved Juli 21， 2018， from COPD Foundation: https://www.copd foundation.org/Learn-More/I-am-aPerson-with-COPD/BreathingTechniques.aspx.

Suhartono, N. K. (2016). Effect of self efficacy pursed lip breathing to decrease tightness and improved oxygen saturation in patients with Chronic Obstructive Pulmonary Disease (COPD). International Journal of Medical Research \& Health Sciences, 5, 3:17-21, diakses pada tanggal 21 juni 2018.

Permadi, A. W. (2017). Pengaruh Pursed
Maximal Inspiration Terhadap Peningkatkan Kekuatan Otot Pernapasan Untuk Mengurangi Keluhan Sesak Napas Pada Kasus Kardio Respirasi. Jurnal Terpadu Ilmu Kesehatan, Volume 6, No 2,November 2017, hlm 118-240, diakses pada tanggal 21 juni 2018

I Kade Wijaya, E. L. (2017). pengaruh Self Care education dan Pursed Lip Breathing exercise terhadap toleransi fisik pada pasien Penyakit Paru Obstruksi Kronis (PPOK). Patria Artha Journal of Nursing Science, Vol. 1(1), 25-35, diakses pada tanggal 21 juni 2018 dari http://ejournal.patriaartha.ac.id/index php/jns.

Douglas, G., Nicol, F., \& Robertson, d. C. (2014). Pemeriksaan klinis. Singapore: Elsevier.

Bicley, L. S. (2012). Buku saku pemeriksaan fisik dan pemeriksaan kesehatan Bates, cetakan 2012. Jakarta: EGC.

Oemiati, R. (2013). Kajian Epidemiologis Penyakit Paru Obstruktif Kronik (PPOK). Media Penelitian dan Pengembangan Kesehatan, 82-88.

Susanti, P. F. (2015). Influence Of Smoking On Chronic Obstructive Influence Of Smoking On Chronic Obstructive (COPD). J Majority, Volume 4 Nomer 5, 67-75.

Lip Breathing Dan Sustained 